\title{
Salmeterol versus formoterol in patients with moderately severe asthma: onset and duration of action
}

\author{
J.A. van Noord*, J.J. Smeets*, J.A.M. Raaijmakers**, \\ A.M. Bommer**, F.P.V. Maesen*
}

Salmeterol versus formoterol in patients with moderately severe asthma: onset and duration of action. J.A. van Noord, J.J. Smeets, J.A.M. Raaijmakers, A.M. Bommer, F.P.V. Maesen. CERS Journals Ltd 1996.

ABSTRACT: We evaluated the profile of the bronchodilatory effect of three inhaled $\beta_{2}$-agonists, $24 \mu \mathrm{g}$ formoterol, $50 \mu \mathrm{g}$ salmeterol and $200 \mu \mathrm{g}$ salbutamol, in patients with stable, moderately severe asthma.

Thirty asthmatics (mean \pm SD age $54 \pm 8$ yrs; forced expiratory volume in one second (FEV1) $58 \pm 12 \%$ predicted; reversibility of FEV1 $21 \pm 8 \%$ from baseline) participated in a single-centre, double-blind, randomized, single-dose, cross-over study. FEV1 was obtained in baseline condition and 10, 20, 30, $60 \mathrm{~min}$, and every hour up to $12 \mathrm{~h}$ after inhalation of the trial drug. Specific airway conductance $(\mathrm{s} G$ aw) was measured at baseline condition and $1,3,5,7,10,20,30,60 \mathrm{~min}$, and every hour up to $12 \mathrm{~h}$ after inhalation.

Formoterol produced a mean increase in $\mathrm{s} G$ aw (as $\%$ of baseline) of $44 \%$ after 1 min, maximal $(135 \%)$ after $2 \mathrm{~h}$, and $56 \%$ after $12 \mathrm{~h}$. The mean increase in FEV was maximal $(27 \%)$ after $2 \mathrm{~h}$, and $10 \%$ after $12 \mathrm{~h}$. After salmeterol, mean increase in $\mathrm{s} G$ aw amounted to $16 \%$ after $3 \mathrm{~min}$, maximal $(111 \%)$ after $2-4 \mathrm{~h}$, and $58 \%$ after $12 \mathrm{~h}$. The mean increase in FEV1 was maximally $25 \%$ after $3 \mathrm{~h}$, being $11 \%$ after $12 \mathrm{~h}$. After salbutamol, mean increase in s $G$ aw was $44 \%$ after 1 min and maximal $(100 \%)$ after 30 min. The peak increase in FEV1 was $25 \%$.

We conclude that formoterol $(24 \mu \mathrm{g})$ and salmeterol $(50 \mu \mathrm{g})$ had an equal bronchodilatory capacity, which was similar to that of $200 \mu \mathrm{g}$ salbutamol and lasted for at least $12 \mathrm{~h}$ in patients with asthma. However, formoterol had a more rapid onset of action than salmeterol, equal to that of salbutamol.

Eur Respir J., 1996, 9, 1684-1688.
*Dept of Respiratory Diseases, De Wever Hospital, Heerlen, The Netherlands. **Dept of Clinical Research, Glaxo BV, Zeist, The Netherlands.

Correspondence: F.P.V. Maesen

Dept of Respiratory Diseases

De Wever Hospital

Henri Dunantstraat 5

6401 CX Heerlen

The Netherlands

Keywords: Asthma

formoterol

salmeterol

Received: October 171995

Accepted after revision March 191996
Formoterol and salmeterol are the first two drugs of a new generation of $\beta_{2}$-agonists with prolonged effect. Both compounds, when administered as an aerosol by a metered-dose inhaler (MDI) or when inhaled as a powder, have the property of retaining a bronchodilatory effect for up to $12 \mathrm{~h}$, which accounts for their use in patients with nocturnal asthma. Moreover, the long duration of action allows for a twice daily treatment frequency, for example, on arising in the morning and on going to bed at night, which could be helpful in promoting patient compliance [1-6].

In vitro work and noncomparative studies on formoterol and salmeterol have shown evidence that there are small differences between the two inhaled drugs with regard to the speed of onset of a bronchodilatory effect, duration of action and dose-dependency of the duration of effect [6-13]. At the present time, a few comparative studies in patients with chronic obstructive pulmonary disease (COPD) have been published [14, 15], however, a direct comparison of the profile of the bronchodilatory effect in asthma is still lacking.

The purpose of the present study was to compare the onset and duration of action of $24 \mu \mathrm{g}$ formoterol, $50 \mu \mathrm{g}$ salmeterol and $200 \mu \mathrm{g}$ salbutamol in patients with moderately severe asthma.

\section{Patients and methods}

Thirty adults with asthma, 8 females and 22 males, who met the American Thoracic Society (ATS) diagnostic criteria for asthma [16], volunteered to participate in the study. To be included in the study they had to fulfil the following criteria: age 18-70 yrs; in a stable phase of asthma, baseline forced expiratory volume in one second (FEV1) $40-80 \%$ of predicted value and not varying more than $15 \%$ over the three study days; reversibility in FEV 1 more than $15 \%$ of the baseline value after 200 $\mu \mathrm{g}$ of inhaled salbutamol via a MDI. They did not suffer from other disorders, for example, liver, kidney or metabolic diseases, and had no history of pulmonary infection or acute exacerbation of their asthma during the previous 6 weeks. None of them used $\beta$-blockers or had taken any experimental drug in the 4 weeks prior to the test. The patients abstained from long-acting $\beta_{2}$-agonists for at least $72 \mathrm{~h}$ prior to the test days, for $36 \mathrm{~h}$ from slow release theophylline, and for $24 \mathrm{~h}$ from oral $\beta_{2}$-agonists, including those with extended effect, and for $8 \mathrm{~h}$ from anticholinergic drugs. The following drugs were permitted if taken in a stable dose: nedocromil sodium, cromolyn sodium, inhaled or oral steroids and antihistamines. Smoking and drinks containing caffeine were forbidden. 
The study was approved by the Medical Ethics Committee of the study hospital, and informed consent was obtained from all the subjects.

The study had a single-centre, double-blind, randomized, single-dose, cross-over design. Each patient received three treatments on different study days with a washout period of 3-7 days between. The patients were allocated to the following three treatments in random order: $200 \mu \mathrm{g}$ salbutamol, $24 \mu \mathrm{g}$ formoterol or $50 \mu \mathrm{g}$ salmeterol, all from a MDI attached to an aerosol chamber (Volumatic @). FEV1 and forced vital capacity (FVC) were obtained in baseline condition and 10, 20, 30, 60 min, and every hour up to $12 \mathrm{~h}$ after inhalation of the trial drug. As a deep inspiration, necessary for the FEV1 manoeuvre, may influence bronchial tone over several minutes, response during the first $10 \mathrm{~min}$ after inhalation was only assessed by the measurement of specific airway conductance ( $\mathrm{s} G \mathrm{aw}$ ). Airway resistance (Raw) and s $G$ aw were obtained at baseline condition and $1,3,5,7$, $10,20,30,60 \mathrm{~min}$, and every hour up to $12 \mathrm{~h}$ after inhalation of the trial drug. Measurements were always started around 08:30 $\mathrm{h}$ and completed around 21:00 h.

In case FEV1 dropped during the day below the baseline value of the relevant day, $200 \mu \mathrm{g}$ salbutamol was given by MDI as rescue medication. FVC and FEV1 were recorded at the mouth using a pneumotachograph with electronic integration. The highest value of three manoevres was retained. Raw and $\mathrm{s} G$ aw were measured in a pressure-compensated integrated flow plethysmograph (Sensormedics 2800 Autobox) as the chord slopes between inspiratory and expiratory flow of $0.5 \mathrm{~L} \cdot \mathrm{s}^{-1}$ at a respiratory rate of $0.5 \mathrm{~Hz}$. Means of nine measurements are reported. Measurements of heart rate and blood pressure were performed in baseline condition, and every hour up to $12 \mathrm{hr}$ after inhalation of the study drug. In addition, before randomization, venous blood and urine samples were collected in the mornings for a safety screen. Any adverse events were carefully noted.

\section{Statistical assessment}

The objective of the trial was to provide evidence about the equivalence of $24 \mu \mathrm{g}$ formoterol and $50 \mu \mathrm{g}$ salmeterol, and about the treatment difference of salbutamol with respect to either formoterol or salmeterol. The two primary outcome variables were FEV 1 and sGaw. The sample size was calculated on 30 patients in order to detect treatment differences with an alpha of 0.025 (twosided) and a power of at least $90 \%$, assuming a standard deviation of $0.62 \mathrm{~L}$ for $\mathrm{FEV} 1[1,3,17]$ and 0.16 $\mathrm{kPa} \cdot \mathrm{L}^{-1} \cdot \mathrm{s}$ for $R$ aw $[18,19]$, a detectable difference of $0.18 \mathrm{~L}$ and $0.10 \mathrm{kPa} \cdot \mathrm{L}^{-1} \cdot \mathrm{s}$ for FEV1 and Raw, respectively, and a correlation coefficient of replicate measurements of $0.9 \mathrm{~L}$ for FEV1 and $0.7 \mathrm{kPa} \cdot \mathrm{L}^{-1} \cdot \mathrm{s}$ for $R$ aw [19].

Changes in FEV 1 and $\mathrm{s} G$ aw from baseline within treatment days were analysed with Student's t-tests per timepoint. Analyses for both efficacy and safety parameters were performed using Student's t-test for testing differences in change from starting level between the treatment periods at each corresponding time-point within the treatment period. An overall test between the treatments was performed by using the area under the curve (AUC), integrating changes from starting level over all time-points in each treatment period, as dependent variable in a repeated measurement analysis of variance (RMAOV). In the latter analysis, two independent factors are involved: treatment period and first order carryover effect, each with three levels.

\section{Results}

The 30 patients who participated in the study all met the inclusion criteria. Their demographic data and baseline lung function are shown in table 1 . The treatment given before the start of the study was as follows: 29 patients took inhaled steroids (average daily dosage 733 $\mu \mathrm{g}), 2$ had oral steroids, 22 short-acting $\beta_{2}$-agonists, and 17 long-acting $\beta_{2}$-agonists, 2 patients took theophylline, 1 terfenadine and 2 acetylcysteine. On the salmeterol and formoterol treatment days, there was no need for rescue medication in any patient. Three patients receiving salbutamol needed rescue medication after 6,7 and $10 \mathrm{~h}$.

The onset of action of salmeterol, formoterol and salbutamol measured as improvement in sGaw and FEV1 is shown in figure 1 and 2 . The time course of the bronchodilation following the three drugs over a period of $12 \mathrm{~h}$ after inhalation is shown in figures 3 and 4 . There were no significant differences in baseline FEV1 and s $G$ aw between the three treatment days. Salbutamol produced a significant increase in $\mathrm{s} G$ aw of $44 \%(\mathrm{p}<0.0001)$ after $1 \mathrm{~min}$, and a maximum increase of $100 \%$ after 30 min, followed by a slow decline. After $5 \mathrm{~h}$, sGaw fell below $20 \%$ of the maximum bronchodilatory capacity (fig. 3 ). The peak increase in FEV1 after salbutamol was $25 \%$ and occurred after $30 \mathrm{~min}$, whereas the FEV1 fell below $20 \%$ of the peak bronchodilating capacity after $5 \mathrm{~h}$.

After the inhalation of formoterol, there was a significant $44 \%$ increase in sGaw after $1 \mathrm{~min}(\mathrm{p}<0.0001)$. Maximum increase in $s G$ aw, achieved after $2 \mathrm{~h}$, amounted to $135 \%$ and afterwards there was a slowly declining plateau, the increase in sGaw after $12 \mathrm{~h}$ still being $56 \%$. The peak increase in FEV1 $2 \mathrm{~h}$ after formoterol was $27 \%$, and after $12 \mathrm{~h}$ the improvement was still $10 \%(\mathrm{p}<0.0001)$.

The inhalation of salmeterol led to significant improvement in sGaw after 3 min $(16 \%$; $<<0.0001)$, whilst the maximum increase $(111 \%)$ was present between 2 and 4 $\mathrm{h}$, and after $12 \mathrm{~h}$ improvement was $58 \%$. The maximum increase in FEV1 was 25\%, and after $12 \mathrm{~h}$ the value of FEV1 was $11 \%$ above baseline $(\mathrm{p}<0.0001)$.

Table 1. - Characteristics of the 30 patients in the study

\begin{tabular}{lc}
\hline Sex F/M & $8 / 22$ \\
Age yrs & $54 \pm 8$ \\
Height cm & $171 \pm 8$ \\
Weight kg & $77 \pm 13$ \\
FEV1 at baseline L & $1.88 \pm 0.60$ \\
FEV1 at baseline \% pred & $58 \pm 12$ \\
FVC at baseline L & $3.15 \pm 0.91$ \\
FVC at baseline \% pred & $90 \pm 12$ \\
$R$ aw at baseline $\mathrm{kPa} \cdot \mathrm{L}^{-1} \cdot \mathrm{s}$ & $0.53 \pm 0.16$ \\
$\mathrm{~s} G$ aw at baseline $\mathrm{kPa} \cdot \mathrm{L}^{-1} \cdot \mathrm{s}$ & $0.46 \pm 0.20$
\end{tabular}

Values are presented as mean \pm SD. F: female; M: male; FEV1: forced expiratory volume in one second; $\%$ pred: percentage of predicted value; FVC: forced vital capacity; Raw: airway resistance; sGaw: specific airway conductance. 


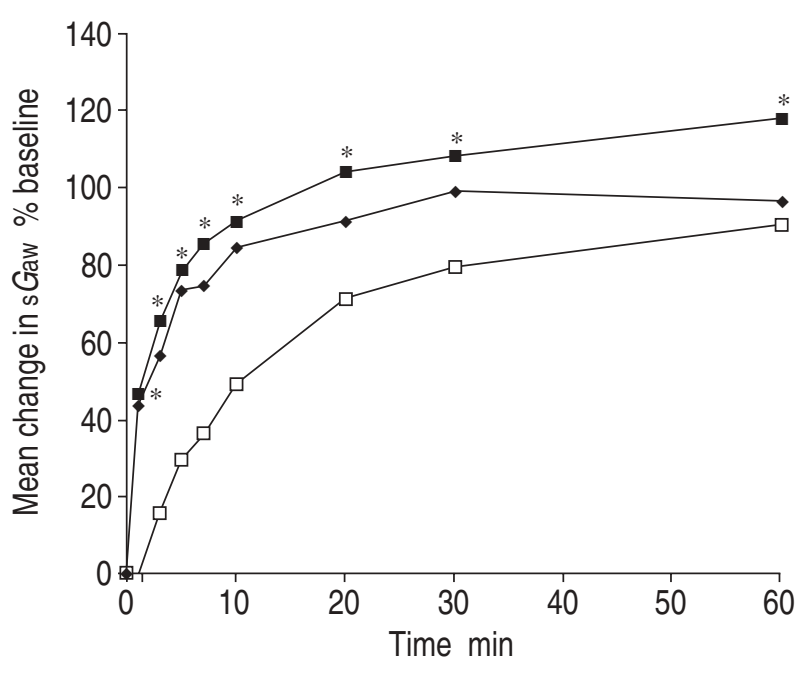

Fig. 1. - Mean change in specific airway conductance (sGaw) (\% baseline) during the first $60 \mathrm{~min}$ after salmeterol, formoterol and salbutamol. Mean baseline s $G$ aw: salmeterol $0.42 \mathrm{kPa}^{-1} \cdot \mathrm{s}^{-1}$; formoterol 0.43 $\mathrm{kPa}^{-1} \cdot \mathrm{s}^{-1}$; salbutamol $0.45 \mathrm{kPa}^{-1} \cdot \mathrm{s}^{-1}$. *: significant difference $(\mathrm{p}<0.05)$ between salmeterol and formoterol. ——: formoterol $24 \mu \mathrm{g} ; \square \square$ : salmeterol $50 \mu \mathrm{g} ; \longrightarrow \longrightarrow$ : salbutamol $200 \mu \mathrm{g}$.

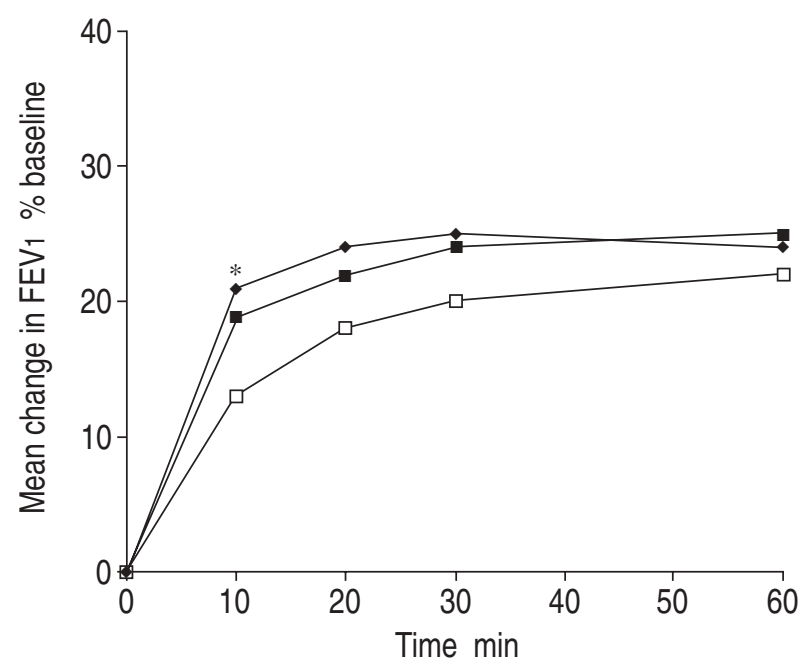

Fig. 2. - Mean change in forced expiratory volume in one second (FEV1) (\% baseline) during the first $60 \mathrm{~min}$ after salmeterol, formoterol and salbutamol. Mean baseline FEV1: salmeterol 1.85 L; formoterol $1.89 \mathrm{~L}$; salbutamol $1.85 \mathrm{~L}$. *: significant difference $(\mathrm{p}<0.05)$ between formoterol and salmeterol. —- formoterol $24 \mu \mathrm{g} ; \longrightarrow \square$ : salmeterol $50 \mu \mathrm{g} ; \longrightarrow$ : salbutamol $200 \mu \mathrm{g}$.

Concerning the onset of action, during the first $2 \mathrm{~h}$ after inhalation the increase in $s G$ aw was greater after formoterol than after salmeterol, and for the increase in FEV1 this was true during the first $10 \mathrm{~min}$. Comparing the onset of action of salbutamol and formoterol, there was no significant difference in the measurements of FEV1 and sGaw during the first hour and $30 \mathrm{~min}$, respectively, but afterwards formoterol caused a greater improvement in both indices.

If we compare the AUC values of the parameters investigated (FEV1, FVC, Raw and sGaw), with the baseline values as minimum after administration of the three drugs (table 2), then it is apparent from the RMAOV that there is no difference between the AUC for formoterol and salmeterol for all parameters. The AUC

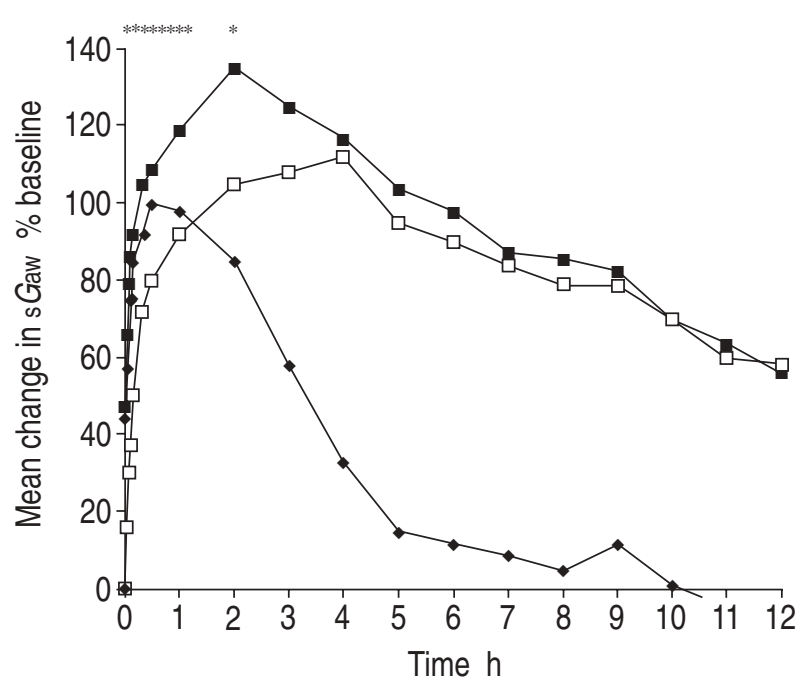

Fig. 3. - Mean change in specific airway conductance (sGaw) (\% baseline) during $12 \mathrm{~h}$ after salmeterol, formoterol and salbutamol. *: significant difference $(\mathrm{p}<0.05)$ between salmeterol and formoterol (see fig. 1 for more details). ——: formoterol $24 \mu \mathrm{g} ; \square \square-$ : salmeterol $50 \mu \mathrm{g} ; \longrightarrow \longrightarrow$ : salbutamol $200 \mu \mathrm{g}$.

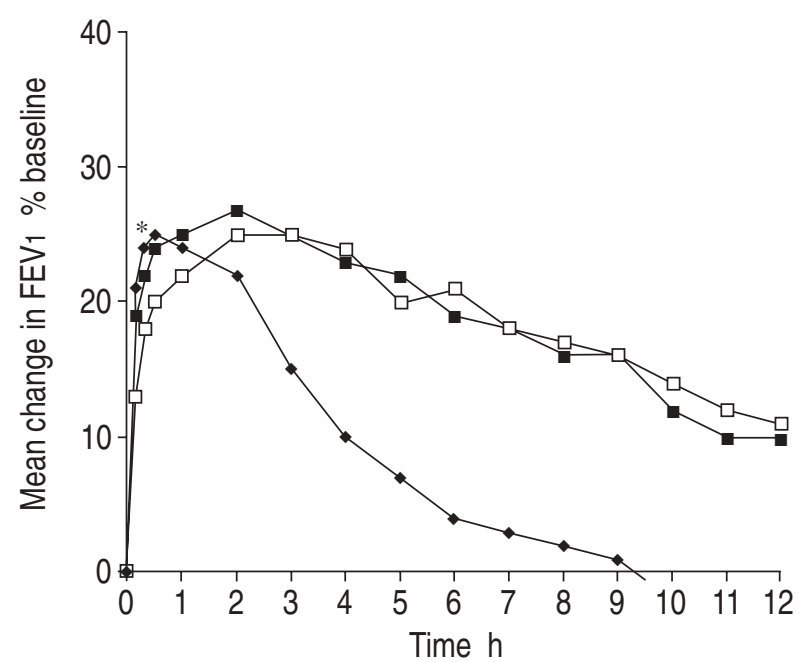

Fig. 4. - Mean change in forced expiratory volume in one second (FEV1) (\% baseline) during $12 \mathrm{~h}$ after salmeterol, formoterol and salbutamol. *: significant difference $(\mathrm{p}<0.05)$ between salmeterol and formoterol at $10 \mathrm{~min}$ (see fig. 2). ——: formoterol $24 \mu \mathrm{g} ; \square \square-$ : salmeterol $50 \mu \mathrm{g} ; \longrightarrow$ : salbutamol $200 \mu \mathrm{g}$.

for both formoterol and salmeterol when compared with that of salbutamol are significantly $(\mathrm{p}<0.02)$ in favour of the former compounds. It should be noted that carryover effects were found with regard to the comparison of salmeterol versus salbutamol $(\mathrm{p}<0.05)$ for $\mathrm{s} G$ aw and $R$ aw. In the RMAOV, treatment effects are adjusted for first order carry-over effects.

There were no significant changes in systolic and diastolic blood pressure except for a drop in the diastolic blood pressure on the formoterol day at the $4 \mathrm{~h}$ time-point. This phenomenon was witnessed previously, directly after the consumption of a warm meal. Heart rate did not change significantly during the three test days.

There were no adverse events reported and the safety screen showed no abnormal data. 
Table 2. - Area under the curve (AUC) of the change in FEV $1, F V C$, sGaw and Raw versus time after $50 \mu \mathrm{g}$ salbutamol, $24 \mu \mathrm{g}$ formoterol and $200 \mu \mathrm{g}$ salmeterol

\begin{tabular}{|c|c|c|c|c|}
\hline & FEV1 & FVC & s $G$ aw & $R$ aw \\
\hline \multicolumn{5}{|c|}{ AUC (treatment) $)^{\#}$} \\
\hline FRM & $4.23 \pm 3.15$ & $4.68 \pm 3.77$ & $4.33 \pm 2.57$ & $-2.30 \pm 1.42$ \\
\hline SLM & $3.88 \pm 3.07$ & $4.71 \pm 4.16$ & $3.73 \pm 2.34$ & $-2.19 \pm 1.51$ \\
\hline SLB & $1.78 \pm 1.75$ & $2.21 \pm 2.55$ & $1.51 \pm 1.27$ & $-0.51 \pm 0.95$ \\
\hline \multicolumn{5}{|c|}{ RMAOV on AUC with baseline as minimum } \\
\hline FRM/SLM & 0.250 & 0.752 & 0.04 & 0.352 \\
\hline FRM/SLB & 0.000 & 0.004 & 0.000 & 0.000 \\
\hline SLM/SLB & 0.000 & 0.005 & 0.000 & 0.000 \\
\hline \multicolumn{5}{|c|}{ Carry over effect } \\
\hline FRM/SLM & 0.302 & 0.401 & 0.461 & 0.310 \\
\hline FRM/SLB & 0.444 & 0.732 & 0.057 & 0.128 \\
\hline SLM/SLB & 0.831 & 0.075 & 0.010 & 0.010 \\
\hline
\end{tabular}

\#: mean \pm SD; $\$$ : p-value. FRM: formoterol; SLM: salmeterol; SLB: salbutamol; RMAOV: repeated measurement analysis of variance. For further definitions see legend to table 1.

\section{Discussion}

This is the first study in which the profile of the bronchodilatory effect of salmeterol and formoterol has been directly compared in patients with stable, moderately severe bronchial asthma. The results demonstrate that, in these patients, $50 \mu \mathrm{g}$ salmeterol and $24 \mu \mathrm{g}$ formoterol inhaled through a MDI have an equal bronchodilatory capacity, which is similar to that of $200 \mu \mathrm{g}$ salbutamol and lasts for at least $12 \mathrm{~h}$. However, formoterol has a more rapid onset of action and bronchodilation is greater than after salmeterol during the first $2 \mathrm{~h}$ postinhalation.

In general, a dose of 12 or $24 \mu \mathrm{g}$ formoterol and 50 or $100 \mu \mathrm{g}$ salmeterol, both twice daily, is recommended for clinical practice. In the present study, we chose to compare $24 \mu \mathrm{g}$ formoterol, the highest clinically recommended dose, with $50 \mu \mathrm{g}$ salmeterol, the lowest recommended dose, hypothesizing after studying data from the literature that these doses might have a comparable duration of action.

In vitro work has shown that formoterol is a more potent $\beta_{2}$-adrenoceptor agonist and has a faster onset of action than salmeterol $[8,9]$, but that the duration of action is longer for salmeterol $[8,9]$. In addition, in vitro, the duration of action of formoterol, but not of salmeterol, was found to be concentration-dependent [9]. Differences in the speed of onset and duration of action between salbutamol, formoterol and salmeterol can be explained by the difference in interaction of these $\beta_{2}$ agonists with $\beta_{2}$-adrenoceptors. Salbutamol is hydrophilic in nature, and interacts directly with the active site of the receptor. Its onset of action will, therefore, be rapid, but because it quickly re-equilibrates with the extracellular aqueous phase, its duration of action will be short [20]. Formoterol is moderately lipophilic. It has the capacity to stimulate the receptor directly, but a significant fraction (500:1) enters the cell membrane in the form of a depot, from where it leaches out gradually to interact with the receptor [21]. The onset of action of formoterol may, therefore, be expected to be either equivalent or slightly slower than salbutamol, but its duration of action will be longer and will depend on the size of the membrane depot. Salmeterol, on the other hand, is highly lipophilic. It is avidly (20,000:1) taken up into the cell membrane, but does not leach out and instead approaches the receptor by slow lateral diffusion through the membrane. Its onset of action will, therefore, be slower than that of salbutamol or formoterol. Once at the receptor, the long side-chain of salmeterol binds to an anchoring site, termed the exosite, which allows the saliformin head of the molecule to repeatedly engage and disengage the active site, resulting in a long duration of action [22].

In asthma, there have been a number of noncomparative studies investigating the effects of formoterol and salmeterol on airway tone. From the studies on formoterol, it seems clear that the 12 and $24 \mu \mathrm{g}$ doses achieve similar peak values of FEV1 [6], and that the onset of action is not dose-dependent [23]. Concerning the duration of action of formoterol, there are conflicting data. In most studies $[1,6]$, the mean bronchodilating effect both of 12 and $24 \mu \mathrm{g}$ formoterol was longer than $12 \mathrm{~h}$. However, in one study [6], there was a considerable variation among the patients, and in another study [10] the bronchodilating effect was less than $12 \mathrm{~h}$ and dose-dependent, i.e. $24 \mu \mathrm{g}$ formoterol showed a longer duration of effect than $12 \mu \mathrm{g}$. From the dose-finding studies on salmeterol it is likely that the registered doses, 50 and $100 \mu \mathrm{g}$ have an equal bronchodilating effect and a similar duration of action of more than $12 \mathrm{~h}$ in patients with moderate asthma [11].

At present, data on direct comparisons between different doses of the two compounds in asthma are not readily available. RABE et al. [24] found that $12 \mu \mathrm{g}$ formoterol and $50 \mu \mathrm{g}$ of salmeterol were equally effective in mild asthmatics in protecting against methacholineinduced bronchoconstriction for up to $24 \mathrm{~h}$. In a study by ZELLWEGER et al. [25], $50 \mu \mathrm{g}$ salmeterol and $24 \mu \mathrm{g}$ formoterol produced comparable protection against methacholine-induced bronchoconstriction during at least $16 \mathrm{~h}$. Cazzola et al. [14] compared the effects of $50 \mu \mathrm{g}$ salmeterol and $24 \mu \mathrm{g}$ formoterol in 16 patients with COPD and concluded that both compounds were equivalent in terms of maximum bronchodilation and duration of action. However, in a second study in patients with COPD, the same authors [15] concluded that $50 \mu \mathrm{g}$ salmeterol had a longer duration of action than 12 or $24 \mu \mathrm{g}$ formoterol.

In our study, $24 \mu \mathrm{g}$ formoterol and $50 \mu \mathrm{g}$ salmeterol both showed a duration of action of at least $12 \mathrm{~h}$. However, it remains to be determined whether we would have obtained different results if we had compared 12 $\mu \mathrm{g}$ formoterol with $50 \mu \mathrm{g}$ salmeterol. Moreover, our results, as in nearly all cross-over studies, were obtained in patients with stable asthma and are not necessarily valid for patients with more serious disease.

What are the clinical and practical implications of the differences between the two long-acting $\beta_{2}$-agonists? The position of these drugs in asthma therapy has not yet been clearly defined. In the guidelines issued by the National Heart, Lung and Blood Institute/World Health Organization (NHLBI/WHO) [26], long-acting inhaled $\beta_{2}$-agonists are recommended as maintenance therapy when standard doses of inhaled corticosteroids fail to achieve control of asthma, especially nocturnal symptoms. As chronic airway inflammation is not modified by these $\beta_{2}$-agonists, other authors prefer to raise the 
dose of inhaled corticosteroids before the prescription of the long-acting $\beta_{2}$-agonists. Under those circumstances, a rapid onset of action, experienced by some asthmatics after inhalation of formoterol as a so-called "kick", is probably not a major advantage, but on the other hand, especially with salmeterol, patients should be instructed to have at hand a short-acting $\beta_{2}$-agonist with a quick response for relief of acute bronchoconstriction.

\section{References}

1. Maesen FPV, Smeets JJ, Gubbelmans HLL, Zweers PGMA. Bronchodilator effect of inhaled formoterol vs salbutamol over 12 hours. Chest 1990; 97: 590-594.

2. Pauwels R, Derom E, Van der Straeten M. Onset of action of beta ${ }_{2}$-agonists by comparison of inhaled formoterol vs inhaled salbutamol. Eur Respir J 1989; 2: $652 \mathrm{~S}$.

3. Maesen FPV, Costongs R, Smeets S, Zweers PGMA, Goedhart DM. Formoterol as dry powder inhalation, a dose-finding study in comparison with formoterol metereddose inhaler and placebo. Chest 1992; 101: 1376-1381.

4. Wallin A, Sandstrom T, Rosenhall L, Melander B. Time course and duration of bronchodilatation with formoterol dry powder in patients with stable asthma. Thorax 1993; 48: 611-614.

5. Boyd G, Anderson K, Carter R. Placebo-controlled comparison of the bronchodilator performance of salmeterol and salbutamol over 12 hours. Thorax 1990; 45: A340.

6. Arvidsson P, Larsson D, Lofdahl CG. Objective and subjective bronchodilation over 12 hours after inhaled formoterol: individual responses. J Asthma 1993; 30: 459-465.

7. Linsen VMJ, Bindels HJC, Van Noord JA. A direct comparison of the time of onset of action between inhaled formoterol and salmeterol. Eur Respir J 1993; 6: S591.

8. Naline E, Zhang Y, Qian Y, et al. Relaxant effects and durations of action of formoterol and salmeterol in the isolated human bronchus. Eur Respir J 1994; 7: 914-920.

9. Nials AT, Coleman RA, Johnson M, Magnussen H, Rabe $\mathrm{KF}$, Vardey CJ. Effects of $\beta$-adrenoceptor agonists in human bronchial smooth muscle. Br J Pharmacol 1993; 110: $1112-1116$.

10. Sykes AP, Ayres JG. A study of the duration of the bronchodilator effect of $12 \mu \mathrm{g}$ and $24 \mu \mathrm{g}$ of inhaled formoterol and $200 \mu \mathrm{g}$ inhaled salbutamol in asthma. Respir Med 1990; 84: 135-138.

11. Kemp JP, Bierman CW, Cocchetto DM. Dose response study of inhaled salmeterol in asthmatic patients with 24 hour spirometry and Holter monitoring. Ann of Allergy 1993; 70: 316-322.

12. Ullman A, Svedmyr N. Salmeterol, a new long-acting inhaled $\beta_{2}$-adrenoceptor agonist: a comparison with salbutamol in adult asthmatic patients. Thorax 1988; 43: 674-678.

13. Lotvall J, Svedmyr N. Salmeterol: an inhaled $\beta_{2}$-agonist with prolonged duration of action. Lung 1993; 171: 249-264.

14. Cazzola M, Santangelo G, Piccolo A, et al. Effect of salmeterol and formoterol in patients with chronic obstructive pulmonary disease. Pulm Pharmacol 1994; 7: 103107.

15. Cazzola M, Matera MG, Santangelo A, Vinciguerra A, Rossi F, D'Amato G. Salmeterol and formoterol in partially reversible severe chronic obstructive pulmonary disease: a dose-response study. Respir Med 1995; 89: 357-362.

16. American Thoracic Society. Standards for the diagnosis and care of patients with COPD and asthma. Am Rev Respir Dis 1987; 136: 225-244.

17. Maesen FPV, Costongs RJMG, Smeets JJ, Brombacher PJ, Zweers PGMA. The effect of maximal doses of formoterol and salbutamol from a metered-dose inhaler on pulse rates, ECG, and serum potassium concentrations. Chest 1991; 99: 1367-1373.

18. Wegener Th, Hedenström H, Melander B. Rapid onset of action of inhaled formoterol in asthmatic patients. Chest 1992; 102: 535-538.

19. Viljanen A. Reference values for spirometric, pulmonary diffusing capacity and body plethysmographic studies. Scand J Clin Lab Invest 1982; 42 (Suppl. 159): 1-50.

20. Anderson GP, Lindén A, Rabe KF. Why are long-acting $\beta$-adrenoceptor agonists long-acting? Eur Respir $J$ 1994; 7: 569-578.

21. Anderson GP. Formoterol: pharmacology, molecular basis of agonism and mechanism of long duration of a highly potent and selective $\beta_{2}$-adrenoceptor agonist bronchodilator. Life Sci 1993; 52: 2145-2160.

22. Johnson M. Salmeterol. Med Res Rev 1995; 15: 225-257.

23. Maesen FPV, Smeets SJ, Costongs MAL, Zweers PGMA, Pfeil JPJ. Onset of action of formoterol by dry powder inhaler: objective and subjective measures. $\mathrm{Br} \mathrm{J} \mathrm{Clin}$ Pharmacol 1995; 49: 294-296.

24. Rabe KF, Jörres R, Nowak D, Behr N, Magnussen H. Comparison of the effect of salmeterol and formoterol on airway tone and responsiveness over 24 hours in bronchial asthma. Am Rev Respir Dis 1993; 147: 14361441.

25. Zellweger JP, Pfenninger M, Ruff P, et al. Twenty four hour protective effect of salmeterol xinafoate $(50 \mu \mathrm{g})$ against methacholine-induced bronchoconstriction in mildto-moderate asthmatic patients; a randomized, doubleblind, cross-over, single-dose trial. Eur Respir J 1994; 7 (Suppl. 18): 422s.

26. NHLBI/WHO Workshop report. Global initiative for asthma. Bethesda, NIH, 1995. 